\title{
The Influence of Culture on the Experience and Interpretation of Disturbing Dreams
}

\author{
Douglas Hollan
}

Published online: 18 April 2009

(C) The Author(s) 2009. This article is published with open access at Springerlink.com

This issue is devoted to an analysis of the relationship between trauma and dreams. With the exception of Deirdre Barrett's 1996 edited volume, this is a relatively understudied subject. Barrett (p. 2) suggests that the lack of attention has come about for two reasons. (i) Until recently many dream researchers-whether or not interested in nightmares and disturbing dreams-following Freud and his theory that dreams are disguised wish fulfillments, have been intent on tracing out the metaphoric and symbolic meanings of dreams rather than investigating what they might be expressing more literally about social and personal experience. (ii) Many trauma researchers, on the other hand, have focused on nightmares and repetitive, intrusive memories and flashbacks more as symptoms of PTSD or other psychiatric disorders, rather than as psychological phenomena worthy of study in themselves. The lack of attention may also have to do with the fact that there is still considerable ambiguity about what should be considered "trauma." This is reflected in Barrett's own organization of chapters: dreams following very severe and disturbing events such as war, incest, rape and firestorms are separated from those following the "Traumas of Normal Living," which range from divorce to bereavement to becoming the recipient of a transplant. The latter types of experiences may surely be quite disturbing for people, but are they "traumatic" in the way we typically use that term?

Barrett (1996, p. 3) notes that one pattern several researchers have found is that dreams immediately following a traumatic or disturbing event are often a fairly literal reenactment of the event, followed by ones that become more metaphoric or symbolic over time:

D. Hollan $(\bowtie)$

Department of Anthropology, University of California, Los Angeles, Los Angeles, CA 90095-1553,

USA

e-mail: dhollan@anthro.ucla.edu 
Several studies have delineated a pattern of post-traumatic nightmares in which the initial dreams are fairly close to a literal reenactment of the trauma, sometimes with the twist that an additional horror, averted in real life, is added to the dream reenactment. Then, as time passes, and especially for those whose PTSD is gradually improving, the dream content begins to make the trauma more symbolic and to interweave it with concerns from the dreamer's daily life.

Barrett does not offer a detailed account of why this pattern might emerge, but others such as Shalev (2005, p. 210), citing a study by Brewin and coworkers (1996), suggest that "traumatic recollections are initially encoded as unelaborated emotional memories and later have to be transformed into autobiographical (episodic) memories through recoding" (orginal emphasis). Presumably this symbolic and temporal transformation of relatively raw sense impressions and perceptions must occur in dream formation and memory as well.

Yet while drawing attention to this developmental pattern, Barrett (1996, p. 4) also cites the work of Hartmann (1984), "who found that some frequent nightmare sufferers can be trauma free and that much horrific dream imagery can be purely metaphoric." And she includes a chapter by Belicki and Cuddy (1996, pp. 52-53), who observe that the dreams of sexually abused women often contain images and themes of violence, rather than sexuality. These violent, metaphoric images appear to capture what the "emotional reality" of the abuse was like, "that for many women the trauma did not feel like a sexual event but an act of profound violence" (p. 53). Finally, Barrett (1996, p. 3) points out that even when trauma dreams follow the literal to metaphoric developmental sequence, their emotional impact on dreamers may vary depending on the way in which they are culturally interpreted. For example, while the dreams of Kuwaitis who had experienced the Iraqi occupation of the early 1990 s tended to become more metaphoric and less literal over time: "They stir up even more fear than in other cultures that the trauma will happen again" (p. 3) because they are interpreted not as reenactments of past traumatic events, but as prophecies of what will happen in the future.

Barrett suggests, then-harkening back to Freud-that the relationship between traumatic events and dream imagery may be more ambiguous and complicated than some have imagined. While some dreams may initially reenact trauma in a fairly literal way, others may be related to it much more indirectly and metaphorically, representing not what actually happened to the dreamer, but what the dreamer felt like or experienced during the event. Further, she hints at how important culture might be in helping people make sense of disturbing dreams, but this remains an undeveloped part of her book. Indeed, we could ask not only how culture affects the interpretation of disturbing dreams, but also how it might affect their formation and experiencing more directly. For example, how does culture influence what we experience as being "traumatic" in the first place? What is the preexisting system of dream beliefs and interpretations that might lend imagery and metaphorical meaning to the representation of trauma in dreams, not only over time but also in the immediate aftermath of the disturbing events? Must "trauma" always involve a threat to the physical existence of a person, or are there culturally constituted threats 
to personhood, status, self-esteem and dignity that can be just as devastating, from a social and psychological point of view? And if so, how might the representation of these social catastrophes be linked to the experience and representation of physical threat, and vice versa? How might culture affect the way in which disturbing dreams are dealt with, whether by inspection and working-through or by denial and repression or some other means?

In the remainder of this Commentary, I discuss how these issues relate to the dream material reported by Hinton et al., Grayman et al. and Jacobson in their articles in this issue. I focus especially on the question of whether the representation of disturbing events in dreams, traumatic-like or otherwise, can ever escape the imprint of culture and its dense webs of interlinked symbols and meanings. I conclude with a discussion of how the concept of "selfscape" dreams (Hollan 2003a, 2004, 2005) might help us illuminate some of the complexity of body-mindevent interactions in the formation, expression and interpretation of disturbing dreams.

\section{Disturbing Dreams and Nightmares in People from Indonesia and Cambodian and Puerto Rican Immigrants to the United States}

All of the papers here report and interpret very disturbing dreams, some clearly related to actual "traumatic" events in the dreamers' lives, some clearly labeled by either dreamers (according to local dream beliefs) or researchers (according to their own "etic" categorizations) as "nightmares" or spirit and incubus attack dreams, some a complex blending of both and some, though disturbing, not clearly related to either trauma or to the "nightmare" label per se. Despite the complexity here, we must try to keep these descriptive and analytical distinctions in mind, first, to avoid comparing apples and oranges across these three samples of dreams and, second, so that we can assess whether such distinctions actually hold up in the way some of the authors propose.

Many of the Cambodian refugees' dreams reported by Hinton et al. are clearly related to their terrible experiences of persecution by and escape from the Pol Pot regime in their native Cambodia-though no doubt exacerbated by their refugee experiences here in the United States and elsewhere (cf. Kinzie 2005). The relationships here among actual traumatic events, Cambodian theories of dreams and personhood and embodied pre- and postdream experiences of panic and anxiety are complex. Many of the refugees dream of encountering the spirits of relatives or others who died during the Pol Pot conflict. These dreams are doubly "traumatic" and "nightmarish" not only because they frequently index and re-present actual horrible events of death and dying, but because they evoke strong dreaming and waking feelings of fear, compassion and responsibility toward these souls of the dead, who are thought to remain anguished and potentially violent until proper Buddhist death rituals or transferences of merit are performed for them.

Hinton et al. describe and analyze very acutely how these dreams, cultural ideas and embodied experiences feed into one another in a circular, reinforcing way and how very difficult and perhaps artificial it is to disentangle them. Dreams of the 
dead, dying and suffering, whether literal representations of actual experiences or metaphorical expressions shaped by Buddhist and cultural notions of the life and death course of souls, evoke powerful feelings of guilt, panic and anxiety, flashbacks and other PTSD-like symptoms, which in turn lead to culturally shaped expectations of more dream encounters with the souls of the dead and aggrieved. Any form of treatment, according to Hinton et al., that might interrupt this cycle, whether pharmacological, psychotherapeutic or cultural practice or ritual meant to acknowledge and assuage the souls of the dead and consolidate a person's sense of "ontological security," might prove helpful with this population.

Grayman et al. also discuss dreams and PTSD symptoms in a postconflict population, in this case, the Acehnese of northern Sumatra. Although Aceh has been embroiled in intermittent colonial and civil wars and political conflict for more than a century, Grayman et al. were surveying mental health needs in the immediate aftermath of the 2005 Helsinki agreement that ended a decades-long war between the Free Aceh Movement and the Indonesian military and government in which thousands of combatants and civilians alike were killed. In a finding similar to one reported by Hinton et al., Grayman et al. observe that "those who described nightmares in general and those who described nightmares about conflict violence are significantly more likely to meet criteria for PTSD than those who did not." Also like Hinton et al., Grayman et al. attempt to situate these disturbing dreams in the context of more general beliefs about dreams and dreaming experiences in Aceh. They note, for example, that Acehnese also commonly dream about meeting with the souls or spirits of deceased relatives and others, that many dreams, especially those that occur repeatedly, are thought to be prophetic in some way and that, in this primarily Muslim society, many "ordinary" nightmares and disturbing dreams are thought to be caused by evil, bad-intentioned jin spirits that attempt to lead dreamers into temptation or openly attempt to attack and kill them. Significantly, these jininspired nightmares do not correlate strongly with PTSD symptoms.

Although Grayman et al. find both "nightmares in general" and dreams about conflict violence correlated with PTSD symptoms, they nevertheless suggest that there is something unique about dreams that depict or replay violent conflict, writing that "Conflict nightmares about the past do not easily fit into Acehnese categories of loempoe, which describe potential futures, and the undesirable varieties of jininspired dreams." Nightmares "that replay terrifying events of the past are as foreign and unrecognizable in the Acehnese dreamscape as the Indonesian troops that perpetrated the dreamers' original traumatic moment." Citing some of the work of Ernest Hartmann (1996) on American Vietnam veterans, Grayman et al. attribute this uniqueness to the fact that posttraumatic dreams associated with PTSD symptoms are not really "dreams" at all but, rather, "memory intrusions" that occur during sleep and are different from non-PTSD-related nightmares in terms of content, repetitiveness, biology and function: "The post-trauma nightmare repeats over and over; the content never changes because it does not become 'absorbed' or 'connected' into accumulated memories."

This is a notable observation and interpretation because it contrasts so sharply with the violence-related dreams reported by Hinton et al.- which are, apparently, more readily encompassed within Cambodian dreamscapes and worldview-and 
with Barrett's (1996) observation, discussed above, that many posttraumatic nightmares do seem to become more symbolic and interwoven with memory and cultural meaning over time. What aspects of culture, worldview, type of violence or embodied experience account for this difference in dreamscapes? In a culture that frames nearly all dream experience as an extension of the life of the soul, one in which those of the living may commingle with those of the dead, and in which many dreams are thought to be prophetic, their meanings and images shared and discussed (at least occasionally), how are disturbing dreams, posttraumatic or otherwise, not given meaning and significance, even if they literally replay past events? What mechanisms or processes, cultural or psychological, can account for this strippingaway of cultural meaning and interpretation, especially in a place where war and conflict have been endemic for a hundred years?

Jacobson reports and analyzes a variety of nightmare experiences from a group of Puerto Rican Americans in the northeastern part of the United States, including spirit and incubus attack dreams and those related to prior sexual, emotional and physical abuse, though not the group-conflict-incited dreams of violence and trauma that Hinton et al. and Grayman et al. feature. Although Jacobson's use of an "altered state of consciousness" perspective on dreams and nightmares is an interesting one and worthy of further discussion, for the purposes of this short Commentary, I focus instead on his effort to situate these dreams culturally and religiously, which makes his article more easily comparable with the other two.

Jacobson emphasizes that his study

underlines the importance of notions such as worldview and behavioral environment for culturally contextualizing the experience, interpretation, and sharing of these [dream] events. Participants' ability and willingness to discuss and characterize these experiences in terms of the spiritual entities recognized by their faiths were facilitated by a general, shared understanding of the existence and occasional appearance of these beings. In this community, the behavioral environment as such is not one in which physiologically inscribed memory traces re-emerge anomalously in a sleeping or hypnotic state. Rather it is one in which, for a spiritualistically and religiously conceived self, dream messages and occasional nightmare visitations provide reminders of a larger, if generally unseen world of moral-religious design and judgment.

In the Puerto Rican American population Jacobson studies, it is Afro-Caribbean folk spiritualism and evangelical and charismatic forms of Christianity that inform the "behavioral environment" and are prime shapers of dream experience and interpretation.

Here again, then, we find a group of people whose worldview and religious and spiritual convictions lead them to perceive and conceptualize continuities, rather than discontinuities, between the waking and the dreaming self. The appearance of spiritual entities in dreams reinforces the apparent truthfulness and validity of the religious systems that posit such entities, while the taken-for-granted nature of the religious systems, in turn, influences the likelihood that certain types of dreams will be experienced, as well as their interpretation. Although Jacobson does not report the kind of looping, mutually reinforcing types of physiology-experience-belief 
interactions that Hinton et al. do, one can well imagine that they exist in this community. The fear that one can be attacked by spiritual entities in dreams could lead to anxiety and panic, which in turn could predispose toward the anticipation and experience of spirit attack and other nightmares, and so on. But equally important, as Hinton et al. note, the taken-for-granted nature of these spiritual entities and resources may be used for solace and protection as well, both within a disturbing dream as it unfolds as well as afterward, as one copes with its emotional consequences. For example, one may pray for comfort and protection from the return of disturbing dreams, whether or not those dreams can be causally linked to prior trauma.

\section{Culture, Trauma and Dreams}

As I mentioned at the outset, an important question about disturbing dreams or nightmares depicting violent or traumatic events is how literal or metaphorical they are. Surely some of them are quite literal re-presentations of harm committed, endured or witnessed. And to this extent, they do resemble, if they are not identical to, intrusive memories and flashbacks that elude integration into a person's day-today patterns of perception, memory and consciousness. Yet there are several reasons why we should remain cautious about just presuming such a transparent connection between image and event. One, of course, has to do with the fallibility of memory and perception itself, whether in dreams or waking life. To the extent that memories and images of any kind are "put-together" and constructed in a present moment, affected by the contemporary interpersonal climate and social demands, they can never be a literal copy of past "reality" (Kandel 2006; Schacter 1996). It is this slippage between event and its representation in memory and dreams that led Freud to begin to theorize a subject-agent who actively experiences, interprets and reacts to disturbing events or trauma, rather than merely undergoing or enduring them and passively displaying their impact in psychiatric symptoms.

A second reason for caution is the extent to which culture insinuates itself not only into the representation of lived events, but also into their experiencing and interpretation in the first place, assuming for the moment the actively experiencing and interpreting subject-agent that Freud eventually posited. For example, surely one of the horrifying aspects of the Pol Pot regime for many Buddhist Cambodians was the fact that it interrupted the cycle of rebirth and merit-making for so many people, not only by killing people directly, but also by preventing the previously dead from receiving their due recognition from the living and by preventing the living from carrying out their sacred obligations to the past and recent dead. This was the perpetration of social death on a mass scale, not just physical death.

This makes the interpretation of violent or scary imagery in any given person's dreams or flashbacks a very challenging undertaking: Is such imagery a representation of actual events witnessed or endured? Or is it the use of jarring, disturbing images, perhaps even culturally derived, to represent something a given person experiences as the personal or cultural equivalent of physical pain and death, such as the loss of loved ones or of one's self-esteem or status, or a paralyzing and self-annihilating sense of 
shame, guilt or humiliation? It is this kind of representational ambiguity that Belicki and Cuddy (1996) were drawing attention to in their study of the dreams of sexually abused women and that leads me to wonder about Hinton and coworkers' rather literal interpretation of their subjects' "asphyxia" dreams as ones indicating actual past experiences of drowning, asphyxiation or shortness of breath.

All of this becomes even more complex when we consider why and how dreams are reported to others (Hollan 2003b), either in the community or at the clinic. In the community, there may be either implicit or explicit rules about the kind of dreams that can be shared and with whom, and narrative templates for what makes a credible report, such as we find among the Acehnese, who are reluctant to discuss dreams that are thought to bear truths or prophecies and who distinguish between "trauma" and "stress" when discussing psychic pain and injury. In the clinic, patients hear of other patients' dreams from other patients or medical personnel, which inevitably must influence which dreams they tend to remember and the way in which they report them. The influence and looping effects of diagnosis and medical expectation on the display and interpretation of psychiatric symptoms have been well documented by Hacking (1995), Young (1995) and others, and is part of the "culture of reporting" that any study of dreams must contend with and deconstruct.

As I reiterate below, none of this is meant to deny that dreams can be nearly literal representations or replays of actual traumatic events witnessed or enduredcertainly they are at times - but merely to remind us that we cannot assume such literalness and transparency. Dreams certainly capture feelings and perspectives on what happens to people, but whether they capture "reality" is another matter.

\section{Coda: Disturbing Dreams and the Self}

Whether or not disturbing dreams or nightmares reported in the aftermath of traumatic events give us an undistorted re-presentation of those events, they tell us something very important about the dreamer's state of self, perhaps at the moment the trauma occurred, but certainly in the present, as the person copes with memories or reminders of past experiences. Indeed, as I have argued elsewhere (Hollan 2003a, 2004, 2005), "selfscape" dreams, those that are visually and emotionally vivid and easy to recall, reflect back to the dreamer, in particular, how his or her current organization of self, whether in pleasure or pain, relates various parts of itself to itself, to its body and to other people and the world. This concept is a play on those used by Fairbairn (1952) and Kohut (1977) to highlight the manifest content of dreams and their relationship to self-organization, as structured by both the interpersonal world and the inner world of internalized objects. But along the lines of Damasio's (1994, 1999) work emphasizing the dependency of the mind on continuously updated representations of the body, it also underscores how dreams may provide a current map or update of the self relative to its own biological underpinnings: thus the "-scape" part of the term. The self emerges and maintains itself in the biological and imaginal space between body and world. Selfscape dreams map this terrain of self-organization, both its inner scapes of body and internalized objects and its outer scapes of other people and the world. 
Selfscape dreams, I suggest, will be found everywhere in the world because they serve a basic feedback function for the self-system. However, their contents will vary considerably, because the relationships of part-self to part-self and of self to world they map and represent will vary considerably from culture to culture and from person to person within the same culture. Further, though selfscape dreams are likely to be found everywhere, only some cultures and groups, like the three discussed in this special issue, explicitly recognize them and seem to take advantage of the feedback they provide. Cultures that focus on dreams, categorize them and label them-especially those that identify some types of dreams as propheticrecognize that some dreams can be related, either directly and indirectly, to the fate and well-being of the dreamer.

The concept of selfscape dreams can help us to think through and analyze disturbing dreams and nightmares because it reminds us that dream processes always engage and implicate self-processes, and so are never mere reflections of the world, other people or the body. In some instances they capture, either fairly literally or fairly metaphorically, the way in which the self is overwhelmed or violated by events or people. In other instances, they may capture how the self is overwhelmed or violated by its own real or imagined impulses, desires, emotions or physiological processes. In some instances, they may capture the ongoing interaction between perturbations from "outside" events and encounters and a person's internalized "state of affairs" (Fairbairn 1952), which are always unique and individualized. But in none of these instances is the imagery of a dream transparent or unambiguous. Indeed we could well imagine the same dream image meaning different things to different people even in the same cultural setting. For example, a dream of asphyxiation might be a fairly literal representation of an experience of torture, but it might also represent a dreamer's sense of choking or suffocating on his or her own fear or dread or guilt. A dream of being shot might be a fairly literal reenactment of an actual attack, but it might also represent a dreamer's sense that he or she deserves to be shot for cowardice or failure to protect him- or herself or others. In all of these examples, the self is overwhelmed or afflicted, but for different, though perhaps interconnected, reasons.

Such ambiguity and fluidity in dreaming processes should also caution us against too readily presuming that dream typologies of different kinds, whether our own etic categorizations or those of the people we study, are necessarily correlated strongly with dream phenomenology. For example, in all three samples here and in many elsewhere (see, e.g., Hollan and Wellenkamp 1994), people often have a special term for "spirit attack" or incubus dreams that distinguish them from other types. Such dreams are often thought to be associated with embodied experiences of choking and suffocation, as a spirit attacks and/or restrains the dreamer, and are thought to occur for particular reasons, for example, the spirit has been offended in some way. But of course such culturally constituted understandings and symbolism could be, and probably are, recruited by dreamers to express other kinds of experiences as well, including perhaps very idiosyncratic ones. For example, used metaphorically, spirit attack images seem an especially apt way of expressing the feeling of being attacked more generally, perhaps as a result of an actual experience of violence or trauma. In this case, recurring dreams of spirit attack, though 
culturally normative in most instances, might themselves be a symptom of a PTSDlike disorder.

Since the dreaming mind transgresses and eludes many cultural and conceptual boundaries, our thinking about it must be fluid and contingent as well.

A final note: Despite my cautionary comments here, I applaud all the authors for accepting Barrett's (1996)challenge to examine more closely how disturbing dreams are related to experiences of trauma. Only such ethnographically grounded studies will enable us to begin to disentangle the body-mind-culture interactions that are a part of every disturbing dream and nightmare, whether or not related to actual trauma and violence.

Acknowledgment I am very grateful to Devon Hinton for asking me to participate in this special issue.

Open Access This article is distributed under the terms of the Creative Commons Attribution Noncommercial License which permits any noncommercial use, distribution, and reproduction in any medium, provided the original author(s) and source are credited.

\section{References}

Barrett, Deirdre, ed.

1996 Trauma and Dreams. Cambridge, MA: Harvard University Press.

Belicki, Kathryn, and Marion Cuddy

1996 Identifying Sexual Trauma Histories from Patterns of Sleep and Dreams. In Trauma and Dreams. Deirdre Barrett, ed., pp. 46-55. Cambridge, MA: Harvard University Press.

Brewin, C.R., T. Dalgleish, and S. Joseph

1996 A Dual Representation Theory of Posttraumatic Stress Disorder. Psychological Review 103(4): 670-686.

Damasio, Antonio R.

1994 Descartes' Error: Emotion, Reason, and the Human Brain. New York: Avon Books.

1999 The feeling of What Happens: Body and Emotion in the Making of Consciousness. New York: Harcourt Brace.

Fairbairn, W. Ronald D.

1952 Psychoanalytic Studies of Personality. London: Tavistock.

Hacking, Ian

1995 Rewriting the Soul: Multiple Personality and the Sciences of Memory. Princeton, NJ: Princeton University Press.

Hartmann, Ernest

1984 The Nightmare: The Psychology and Biology of Terrifying Dreams. New York: Basic Books.

1996 Who Develops PTSD Nightmares and Who Doesn't. In Trauma and Dreams. Deirdre Barrett, ed., pp. 100-113. Cambridge, MA: Harvard University Press.

Hollan, Douglas

2003a Selfscape Dreams. In Dreaming and the Self: New Perspectives on Subjectivity, Identity, and Emotion. Jeannette Marie Mageo, ed., pp. 61-74. Albany: State University of New York Press.

2003b The Cultural and Intersubjective Context of Dream Remembrance and Reporting: Dreams, Aging, and the Anthropological Encounter in Toraja, Indonesia. In Dream Travelers of the Western Pacific: Sleep Experiences and Culture in the Western Pacific. Roger Ivar Lohmann, ed., pp. 169-187. New York: Palgrave.

2004 The Anthropology of Dreaming: Selfscape Dreams. Dreaming 14: 170-182.

2005 Dreaming in a Global World. In A Companion to Psychological Anthropology. Conerly Casey and Robert B. Edgerton, eds., pp. 90-102. Malden, MA: Blackwell. 
Hollan, Douglas W., and Jane C. Wellenkamp

1994 Contentment and Suffering: Culture and Experience in Toraja. New York: Columbia University Press.

Kandel, Eric R.

2006 In Search of Memory: The Emergence of a New Science of Mind. New York: W. W. Norton. Kinzie, J.D.

2005 PTSD among Traumatized Refugees. In Understanding Trauma: Integrating Biological, Clinical, and Cultural Perspectives. Laurence J. Kirmayer, Robert Lemelson, and Mark Barad, eds., pp.

Kohut, Heinz 194-206. New York: Cambridge University Press.

1977 The Restoration of the Self. Madison, WI: International Universities Press.

Schacter, Daniel L.

1996 Searching for Memory: The Brain, the Mind, and the Past. New York: Basic Books.

Shalev, Arieh Y.

2005 PTSD: A Disorder of Recovery? In Understanding Trauma: Integrating Biological, Clinical, and Cultural Perspectives. Laurence J. Kirmayer, Robert Lemelson, and Mark Barad, eds., pp. 207223. New York: Cambridge University Press.

Young, Alan

1995 The Harmony of Illusions: Inventing Post-Traumatic Stress Disorder. Princeton, NJ: Princeton University Press. 